^VIBEYOR

\title{
Influence of the Sintering Conditions on the Properties of PM Materials
}

\section{$P$ Delarbre* and B Hornof}

\author{
Research and Development Department, PMG Füssen GmbH, Germany
}

\begin{abstract}
The present paper reports the effect of the three steps of the sintering conditions - dewaxing - sintering - cooling- on the properties of PM steels. Three grades of PM materials have been studied with three different alloying elements. The effect of a copper (mixing), a chromium (prealloyed) and a silicon (prealloyed) addition to iron powder for production of motor parts, synchronizer parts and soft magnetic materials is investigated. The beneficial effect of the different allowing elements depends strongly of the sintering conditions like dewaxing, sintering protective atmosphere and cooling rate in industrial equipment. The support of a metallurgical examination can explain and resolve the responsible mechanism for anomalous behavior of the mechanical properties.
\end{abstract}

\section{Keywords}

Chromium, Silicon, Copper, Iron powder, Sintering, Microstructure

\section{Introduction}

Powder metallurgy is a process, which has the capability to produce parts of higher shape complexity and with high performance. These performances could be obtained in the last years by further development of compacting system and a new generation of continuous sintering furnace.

Sintering is the process by which metal powder compacts are transformed into coherent solid at temperatures below their melting point. During sintering, the powder particles are bonded together by diffusion and other atomic transport mechanisms. The specimen acquires a certain mechanical property in relation to the microstructure. The design of the sample is not distorted.

The green part with a density between $6.8-7.3 \mathrm{~g} / \mathrm{cm}^{3}$ has a porous structure whose the surface is for this reason in oxidizing condition. Consequently, the sintering atmosphere is to protect the powder compacting particles during the sintering and to reduce residual surface oxides must have a reducing effect. There are several possible reasons for selecting a particular atmosphere for sintering metal powders. Most all metals require some form of protection from oxidation during sintering [1,2]. The sintering atmosphere in the furnace consists generally on a gas mixture nitrogen - hydrogen in a different composition or an endothermic gas to protect the ferrous product from oxidation during the sintering cycle.

\section{Materials and Experimental Methods}

\section{PM materials}

The investigated power mixes with their chemical composition are listed in Table 1.

\section{Protective atmosphere}

The behavior of the different gas in a sintering furnace has been mentioned in the Table 2. The figure shows that the water vapour condense, the carbon dioxide and oxygen has oxidizing - decarburizing effect and hydrogen reducing and carbon monoxide reducing - carbonizing. The carbon monoxide can be converted to carbon diox-

*Corresponding author: P Delarbre, Research and Development Department, PMG Füssen GmbH, Germany, E-mail: Patrice.Delarbre@pmgsinter.com

Received: February 23, 2018: Accepted: April 28, 2018: Published: April 30, 2018

Copyright: (c) 2018 Delarbre P, et al. This is an open-access article distributed under the terms of the Creative Commons Attribution License, which permits unrestricted use, distribution, and reproduction in any medium, provided the original author and source are credited. 


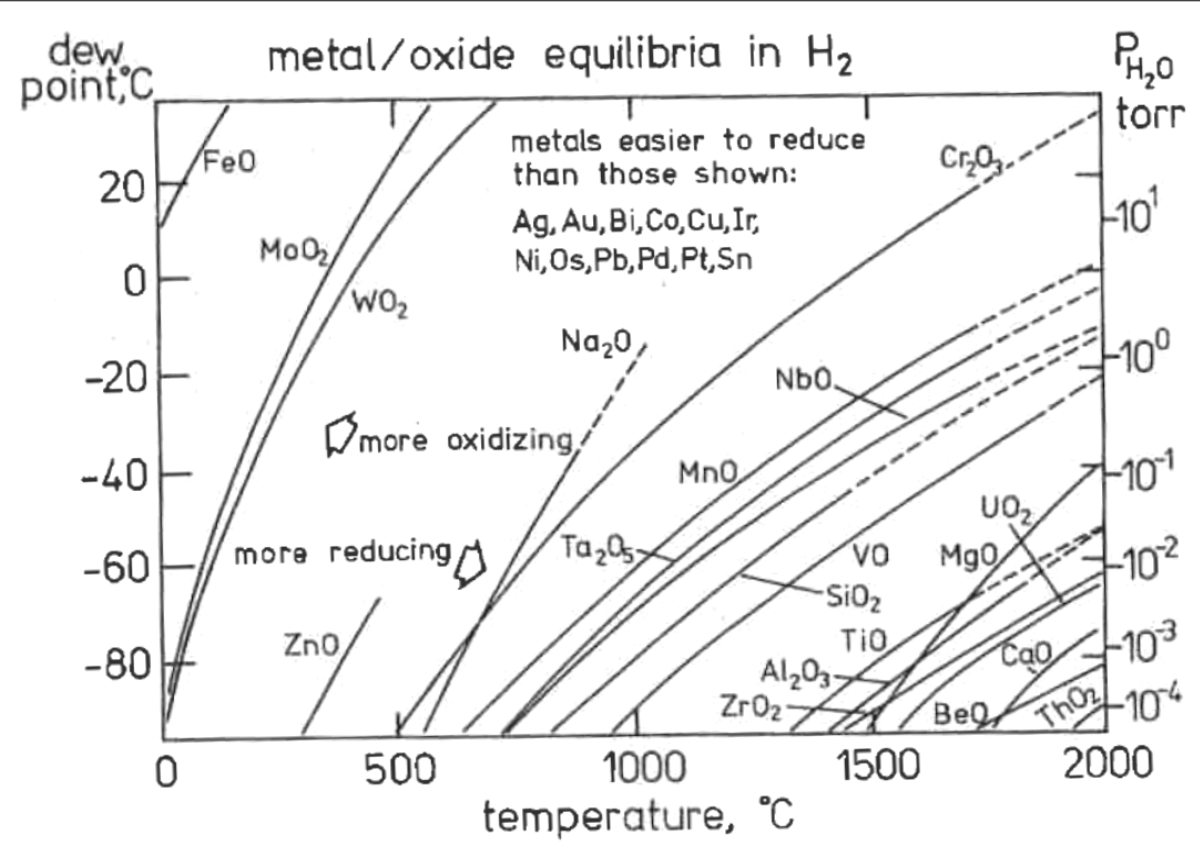

Figure 1: Equilibrium conditions for metal oxides and metals in a pure reducing atmosphere [5].

Table 1: Nominal chemical composition of the investigated powers.

\begin{tabular}{|l|l|l|l|l|l|l|l|}
\hline Base power & & Fe & Cu & Ni & Cr & Mo & Si \\
\hline FeCu & Mixing & Rest & 1.5 & $\ldots$ & $\ldots$ & $\ldots$. & $\ldots$. \\
\hline Fe-CrMoC & Prealloyed & Rest & $\ldots$ & $\ldots$ & 3 & 0.5 & $\ldots$. \\
\hline Fe-Si & Prealloyed & Rest & $\ldots$ & $\ldots$ & $\ldots$ & $\ldots$. & 3 \\
\hline Fe-CrNiMo & Prealloyed & Rest & $\ldots$ & 13 & 17 & 2.2 & 0.8 \\
\hline
\end{tabular}

Table 2: The important gas in the sintering atmosphere.

\begin{tabular}{|l|l|l|l|l|}
\hline Neutral & Reducing & Oxidizing & Decarbonizing & Carbonizing \\
\hline $\mathrm{N}_{2}$ & $\mathrm{H}_{2}$ & $\mathrm{H}_{2} \mathrm{O}$ & $\mathrm{H}_{2} \mathrm{O}$ & $\mathrm{CO}$ \\
\hline $\mathrm{Ar}$ & $\mathrm{CO}$ & $\mathrm{CO}_{2}$ & $\mathrm{CO}_{2}$ & $\mathrm{C}_{\mathrm{m}} \mathrm{H}_{\mathrm{n}}$ \\
\hline $\mathrm{He}$ & & $\mathrm{O}_{2}$ & $\mathrm{O}_{2}$ & \\
\hline
\end{tabular}

ide. Nitrogen, Argon and Helium are usually considered like inert atmospheres. Only argon and helium are inert in the sense they do not react chemically. Argon and helium have been rarely used as furnace atmospheres because of their high cost [3].

Nitrogen is unreactive, although the stability of the $\mathrm{N}_{2}$ molecule normally makes it. Usually parts are sintered in nitrogen - hydrogen protective atmosphere containing a hydrogen between 10 and $30 \%$. That atmosphere is generally introduced in the transition zone located between the high heat zone and cooling zone of the furnace. The flow of the $\mathrm{N}_{2}-\mathrm{H}_{2}$ atmosphere is selected so that the atmosphere eliminated the infiltration of air into the furnace.

The Figure 1 shows the influence of the temperature and of the dew point or water vapor content for reduction of various oxides in pure hydrogen [4-6]. The dew point is a measure of the water to hydrogen partial pressure ratio and gives the temperature at which water vapor condense. A dew point of $6{ }^{\circ} \mathrm{C}$ corresponds to $1 \mathrm{vol}$.
$\%$ water content in the atmosphere. The advantage of the diagram is that it gives the profile line for the oxidizing reducing of the alloying elements. The line of the metals situated at low dew point has the great affinity to oxygen and for this reason, the sintering conditions are more important for the obtainment of good sintering necks, which lead to high performance mechanical properties.

\section{Sintering furnaces}

Continuous furnaces used in large scale sintering in protective atmospheres of structural parts are listed in the Table 3.

The furnace type and dimensions depends on the production quantity, chemical composition of the PM steel, operation costs, type of atmosphere, cooling rate.

During the sintering process a wide variety of physi$\mathrm{cal}$, chemical and metallurgical phenomena occur within the mass of metal powder particles. These effects have been influenced by the sintering conditions and by the sintering atmosphere. The typical process control factors for a furnace that are recognized in order to produce good reproducibility of the quality of the sintering parts are the following:

- Measure of the sintering temperature

- Measure of the dew point 


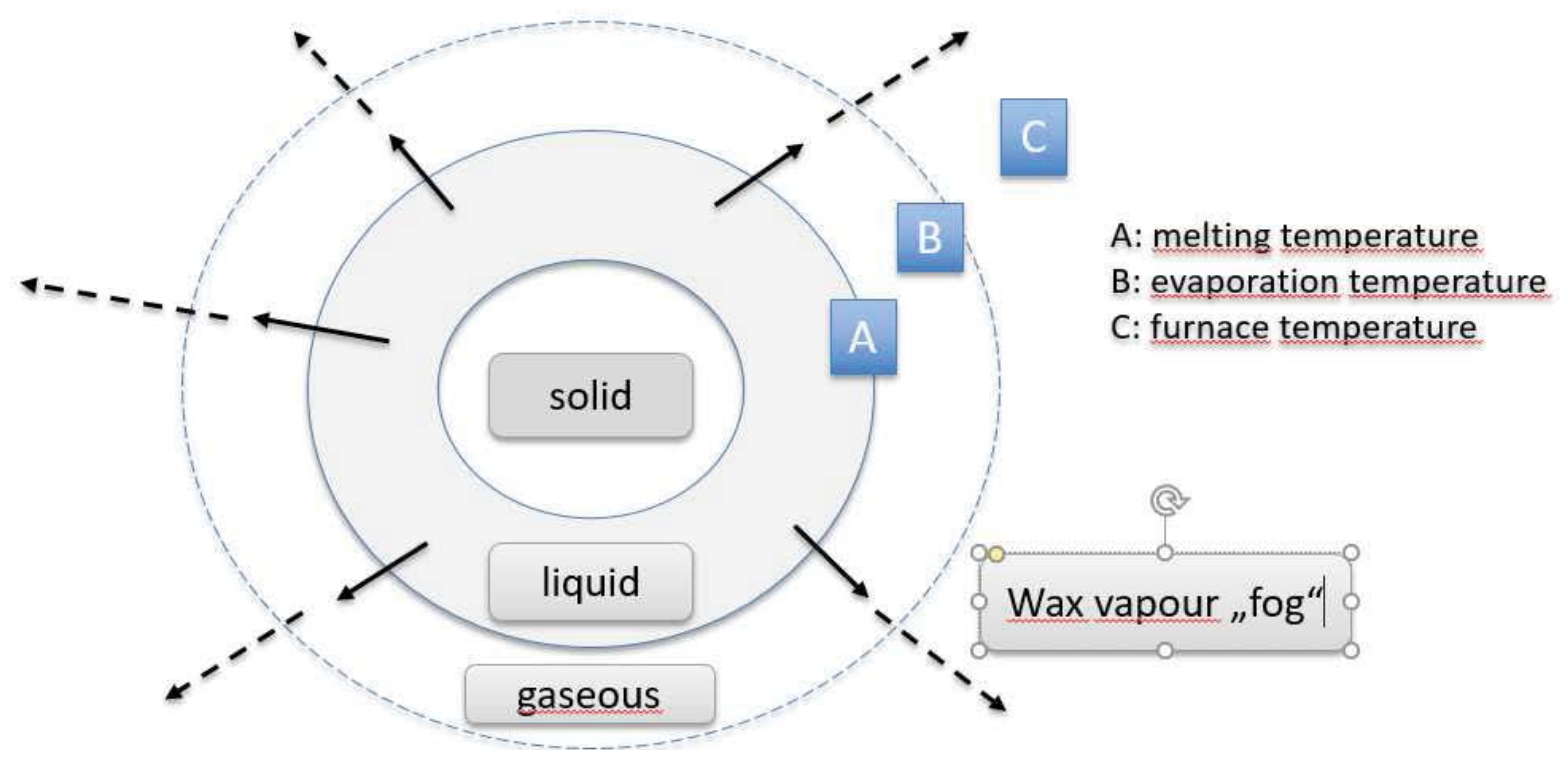

Figure 2: Principe general of the dewaxing.

Table 3: Description of the three sintering furnaces.

\begin{tabular}{|l|l|l|l|}
\hline & Mesh belt furnace & Walking beam furnace & Roller furnace \\
\hline Protective atmosphere & Nitrogen - hydrogen Endothermic atmosphere & Nitrogen - hydrogen & Nitrogen - hydrogen \\
\hline Rapid cooling & Nitrogen - hydrogen Endothermic atmosphere & Difficult & Possible \\
\hline Sintering temperature & $1120^{\circ} \mathrm{C}$ & $1120-1250^{\circ} \mathrm{C}$ & $1120-1200{ }^{\circ} \mathrm{C}$ \\
\hline Transport system & Mesh belt & Walking beam & Roller system \\
\hline Length $(\mathrm{mm})$ & $2000-2500$ & $2000-3000$ & $1800-2400$ \\
\hline
\end{tabular}

Table 4: Schematically representation of the three zones with the goal of the three zones.

\begin{tabular}{|l|l|l|l|}
\hline & & Processus & $\begin{array}{l}\text { Temperature } \\
\left({ }^{\circ} \mathbf{C}\right)\end{array}$ \\
\hline \multirow{5}{*}{ Dewaxing zone } & 1 & Dewaxing (liquid) & $150-200$ \\
\cline { 2 - 3 } & 2 & Dewaxing (gas) & $300-800$ \\
\hline \multirow{3}{*}{ Sintering zone } & 3 & Reducing & $800-1000$ \\
& 4 & Diffusion of carbon & $900-1050$ \\
\cline { 2 - 3 } & 5 & $\begin{array}{l}\text { Decarburation } \\
\text { (atmosphere) }\end{array}$ & $1000-1300$ \\
\hline Cooling zone & 6 & Carburation (atmosphere) & $1050-800$ \\
& 7 & Microstructure & $950-300$ \\
& 8 & Cooling & $300-50$ \\
\hline
\end{tabular}

- Measure of the oxygen content with an oxygen sensor

- Furnace temperature profile

- Furnace cooling rate

- Furnace atmosphere volume and composition

- Atmosphere location and direction

The sintering process has been divided into three steps (Table 4):

- First step: Dewaxing to eliminate the lubricant in the green part between $300{ }^{\circ} \mathrm{C}$ et $800{ }^{\circ} \mathrm{C}$

- Second step: Sintering at temperature between 1120 and $1250{ }^{\circ} \mathrm{C}$ for the formation of solid bridges or necks between the individual powder particles

- Third step: Cooling or rapid cooling to obtain the microstructure and the mechanical properties

\section{Results and Discussion}

\section{Dewaxing}

The delubrication or dewaxing is the major challenge with sintering process. In order to obtain the sufficient delubrication the furnace should be supplied with an appropriate furnace atmosphere correctly distributed between the furnace zones.

The lubricant, which is mixed with the powder for better compaction, is volatile and will in air, is organic substance with a long carbon chain for example wax with the chemical formula $\mathrm{CH}_{3}\left(\mathrm{CH}_{2}\right)_{16} \mathrm{CO}_{2} \mathrm{H}$. The melting point is about $70-150{ }^{\circ} \mathrm{C}$ and the evaporation temperature $150-350{ }^{\circ} \mathrm{C}$. Thar lubricant is the most commonly used in the PM industry for conventional compaction of ferrous materials.

The lubricants like zinc stearate with the formula $\mathrm{Zn}$ $\left(\mathrm{C}_{18} \mathrm{H}_{35} \mathrm{O}_{2}\right)_{2}$ is a white, hydrophobic powder with a slight, characteristic odor and lithium stearate with the formula $\mathrm{LiC}_{18} \mathrm{H}_{35} \mathrm{O}_{2}$ is, a white soft solid. The serious disadvantage of the two lubricants is that a relatively high flow of pro- 
tective atmosphere through the furnace is necessary to remove a soap component of zinc or lithium stearate and to avoid the agglomeration of the vapor with zinc or lithium on the walls of the furnace and make housekeeping and maintenance of furnace equipment more complex.

The decomposition of the lubricant is represented in the Figure 2. At room temperature the lubricant is in a solid state. With increasing the temperature, the transformation solid - liquid takes place and the formation of wax vapour condense is the final state.

The dewaxing step can take place under a wet - oxidizing atmosphere under a dry and reducing. The two different mechanisms are described in Figure $3 \mathrm{a}$ and Figure $3 \mathrm{~b}$.
The dewaxing under dry and reducing condition (low dew point in the dewaxing zone) leads to catastrophic effects of poor lubricant removal and the formation of microcrack at the sintering surface of the part appear (Figure 4).

The microscopic image permits to identify the presence of a microcrack at the surface on the part. The SEM image shows clearly that the surface of the microcrak is free of sintering broken necks between the powder particles.

Granular soot appears mainly on the top surface of the parts and potentially causing carburization and embrittlement.

The dewaxing under wet and oxidising condition with the presence of oxygen and water vapor has the
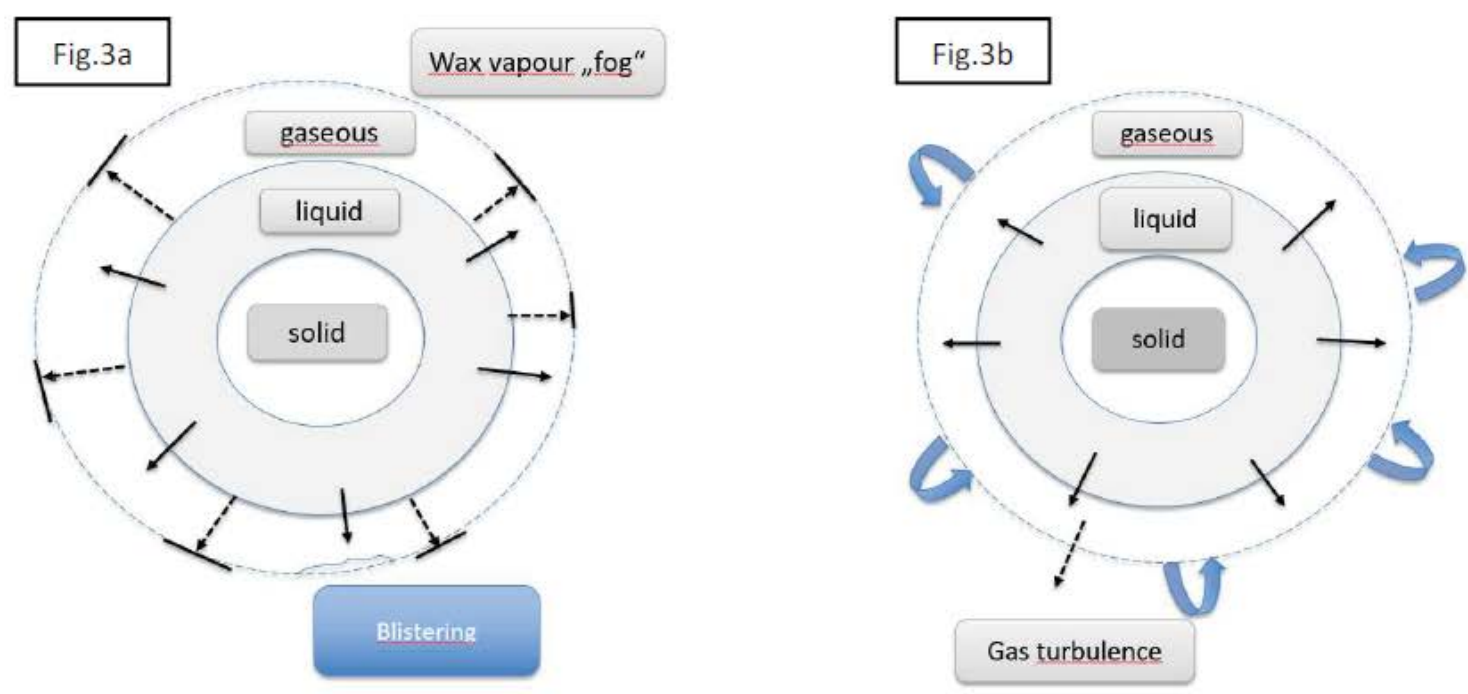

$$
\begin{gathered}
\mathrm{C}_{\mathrm{M}} \mathrm{H}_{\mathrm{N}}+\left(\mathrm{H}_{2}+\mathrm{CO}+\mathrm{N}_{2}\right) \\
\mathrm{C}_{\text {soot }}+\mathrm{H}_{2}+\mathrm{CO}+\mathrm{N}_{2}
\end{gathered}
$$

$$
\begin{gathered}
\mathrm{C}_{\mathrm{M}} \mathrm{H}_{\mathrm{N}}+\left(\mathrm{H}_{2} \mathrm{O}+\mathrm{CO}_{2}+\mathrm{N}_{2}+\mathrm{O}_{2}\right) \\
\mathrm{H}_{2}+\mathrm{CO}+\left(\mathrm{H}_{2} \mathrm{O}+\mathrm{CO}_{2}+\mathrm{N}_{2}\right)+\mathrm{C}_{\text {soot }}
\end{gathered}
$$

Figure 3: Schematically representation of dewaxing under dry (Figure 3a) and wet (Figure 3b) condition.
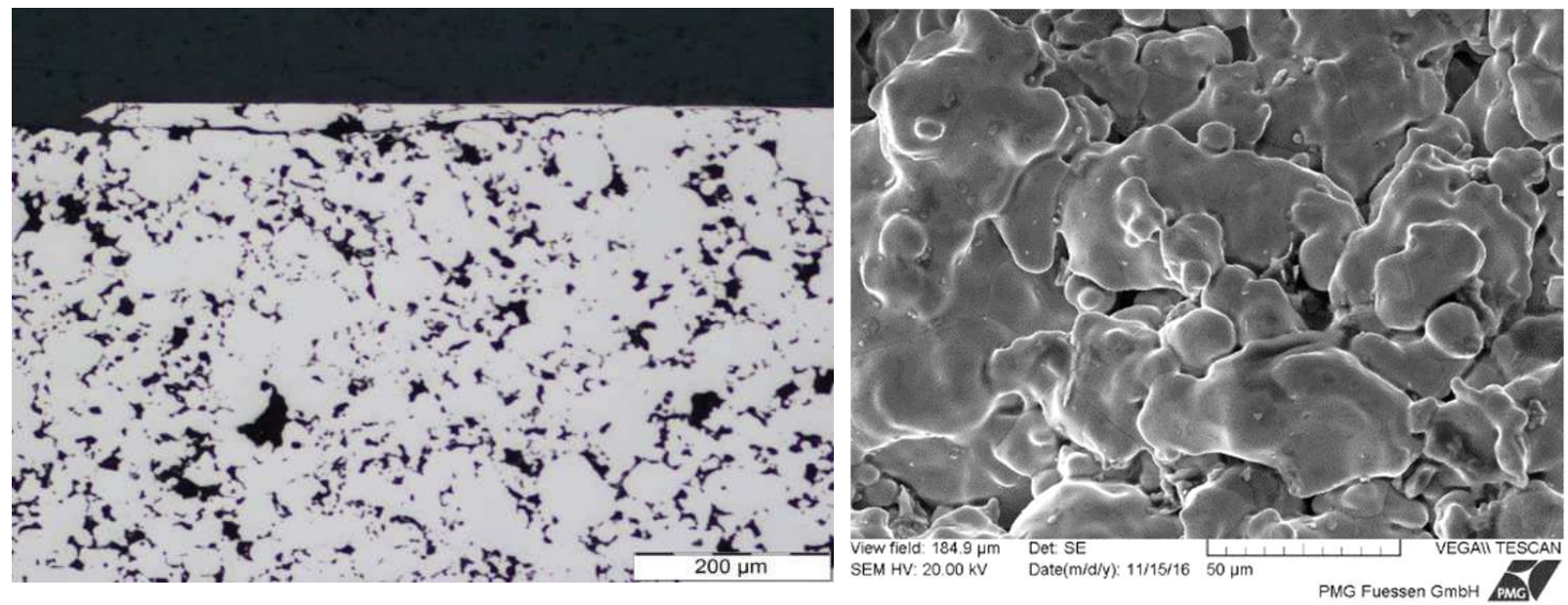

Figure 4: Formation of blistering at the surface of a specimen. 
capability to remove the lubricant and the formation of blistering does not appear. The oxidising reaction will sometimes form a superficial oxide on the powders. This oxide will be reduced during the sintering cycle.

Under the wet and oxidising condition a dewaxing with a " rapid burn off $=\mathrm{RBO}$ » can be installed. The advantage of the system is to reduce the time for the dewaxing and to avoid the formation of soot on the surface of the parts as well as on the surface of the internal wall of the furnace.

\section{Sintering}

After the dewaxing, the sintering process is the next step.

- Reduction of metal (metal oxide $=>$ metal + oxygen)

- Formation of sintering bridges or necks

- Avoid a decarburization of the part

Sintering time and sintering temperature and the protective atmosphere are the important parameters to obtain the best mechanical properties. The properties depend also strongly on the type powder (for example powder with master-alloy, bonded powder), and on the chemical composition (quantity of nickel, copper and carbon).

The sintering temperature for the $\mathrm{P} / \mathrm{M}$ steels is between $1120^{\circ} \mathrm{C}$ and $1290{ }^{\circ} \mathrm{C}$ - generally $1120^{\circ} \mathrm{C}$ - under endothermic gas or nitrogen - hydrogen.

\section{Influence of the protective atmosphere}

The protective atmosphere with a reducing character permit to create the formation of solid sintering bridges or necks between the metallic surfaces of the particles (Figure 5a). An oxidation of the iron chromium powder surface particles (Figure $5 \mathrm{~b}$ ) during the sintering process hinder diffusion bonding and the development of the adequate mechanical properties. The atmosphere composition and specially the water vapor condense is responsible for this effect.

\section{Influence of the sintering temperature for the $\mathrm{P} / \mathrm{M} \mathrm{FeCuC}$}

The Figure 6a shows an example of the microstructure of the $\mathrm{PM}$ steel $\mathrm{FeCuC}$, which has been sintered at a temperature under the melting point $\left(1083^{\circ} \mathrm{C}\right)$ of the element copper. The powder particles with a size of 60
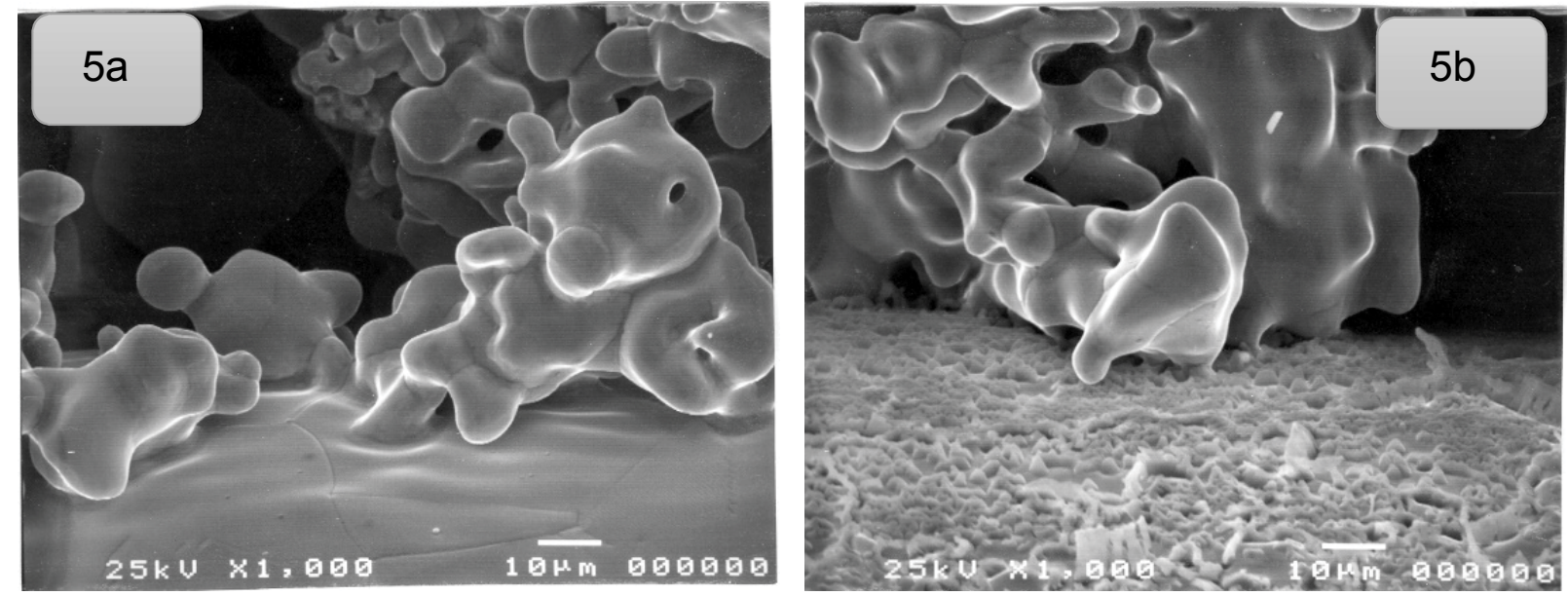

Figure 5: Formation of sintering bridge metal-metal (a); and metal-oxide (b).
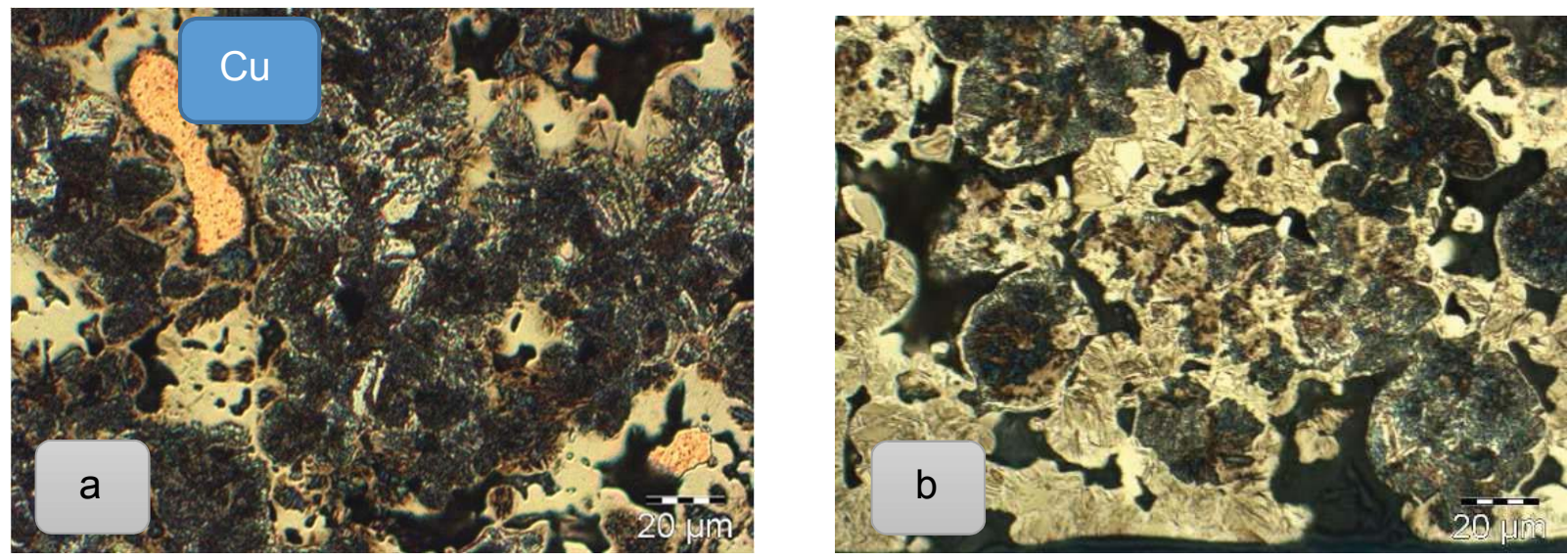

Figure 6: Inadequate sinter of $\mathrm{FeCu}$ at $1050^{\circ} \mathrm{C}$ (a) and desirable sinter at $1120^{\circ} \mathrm{C}(\mathrm{b})$. 
$\mu \mathrm{m}$ can be easily detected. The copper is here not dissolved in $\gamma$ - iron (austenite). At sintering temperature $1120^{\circ} \mathrm{C}$ i.e. $>1083^{\circ} \mathrm{C}$ the copper particles have diffused relatively easily and are dissolved into the iron matrix (Figure 6b). The macro-hardness of the material with the dissolved copper particles (Figure $6 \mathrm{~b}$ ) is higher that the macro-hardness of the material with undissolved copper particles (Figure 6a).

\section{Influence of the dew point for the P/M FeCrMoC}

The influence of the dew point is clearly to understand with the following sample. A specimen made of $\mathrm{Fe} 3.0 \mathrm{Cr} 0.5 \mathrm{Mo} 0.5 \mathrm{C}$ compacted with a green density of $6.9 \mathrm{~g} / \mathrm{cm}^{3}$ has been sintered under the two conditions:

Figure 7a: $1120^{\circ} \mathrm{C} /$ nitrogen - hydrogen/dew point $10{ }^{\circ} \mathrm{C} /$ cooling rate $3{ }^{\circ} \mathrm{C} / \mathrm{s}$
Figure $7 \mathrm{~b}: 1120^{\circ} \mathrm{C} /$ nitrogen - hydrogen/dew point $30{ }^{\circ} \mathrm{C} /$ cooling rate $3{ }^{\circ} \mathrm{C} / \mathrm{s}$

Sintering temperature and cooling rate are the same but the dew point are two different values.

The microstructure of the sintering by a dew point of $-10^{\circ} \mathrm{C}$ shows undesirable particle boundaries with sharp angular pores due to poor reducing atmosphere (Figure 7a). Decarburization and oxygen pickup take place during the sintering due to a dew point $-10{ }^{\circ} \mathrm{C}$ and are responsible for the low macrohardness. A formation of a thin oxide layer on the surface of the powder particles can be seen and is an obstacle for the formation of good sintering necks (Figure $7 \mathrm{c}$ ). The Figure $7 \mathrm{~b}$ shows a very good particle to particle bonding without the formation of a oxide layer between the powder particles. The SEM
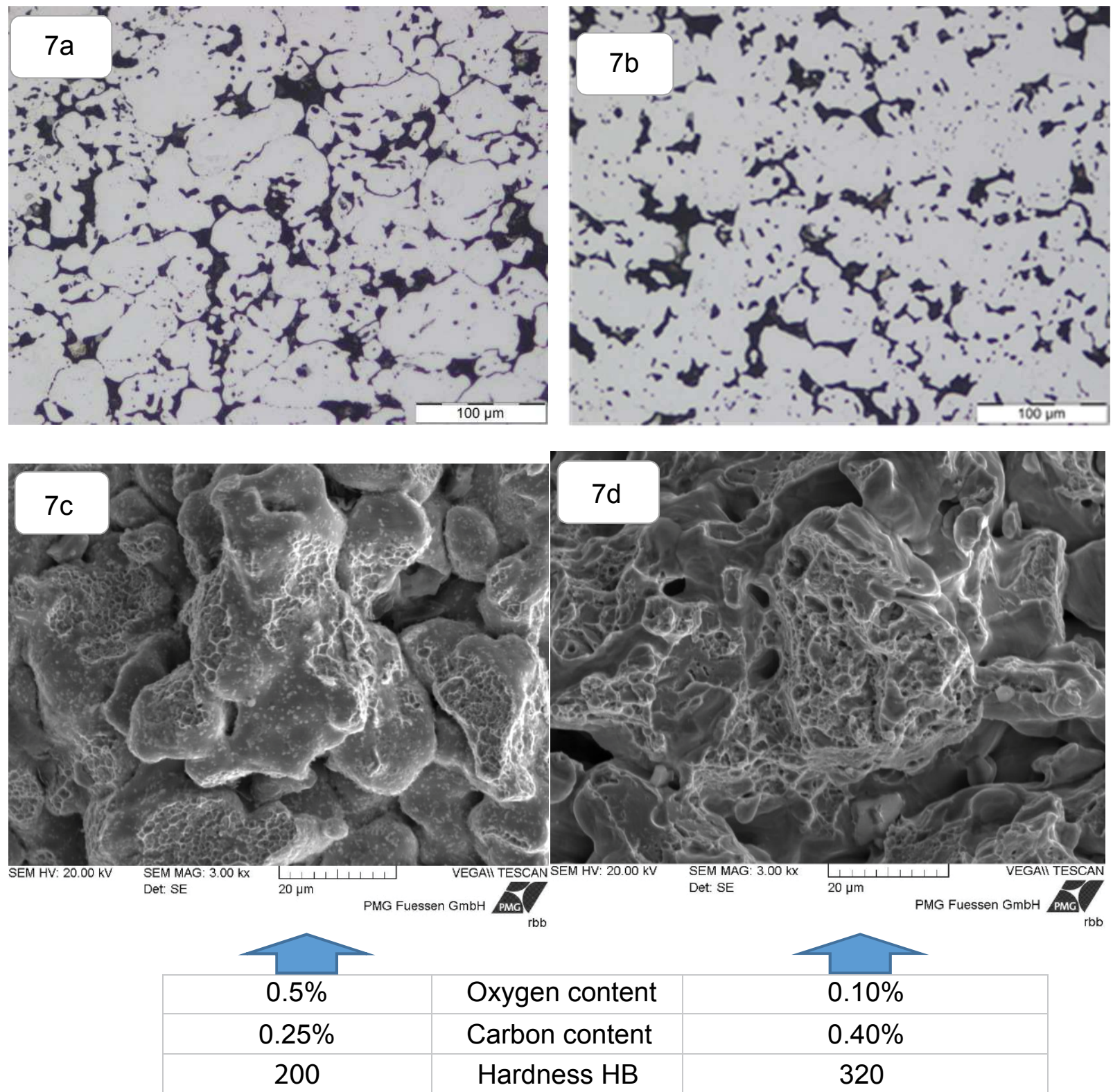

Figure 7: Micrographs in unetched state. a) $1120{ }^{\circ} \mathrm{C} /$ nitrogen - hydrogen/dew point $-10{ }^{\circ} \mathrm{C} / \mathrm{cooling}$ rate $3{ }^{\circ} \mathrm{C} / \mathrm{s}$; b) $1120{ }^{\circ} \mathrm{C} /$ nitrogen - hydrogen/dew point - $30^{\circ} \mathrm{C} /$ cooling rate $3{ }^{\circ} \mathrm{C} / \mathrm{s} ; \mathrm{c}, \mathrm{d}$ ) SEM macrographs of a fracture surface. 
micrograph (Figure $7 \mathrm{~d}$ ) confirm the effect due to the formation of many broken sintering necks.

\section{Influence of the sintering temperature and the protective gas for $\mathrm{P} / \mathrm{M}$ FeSi}

The main application of Fe-Si material is in the field of soft magnetic materials for alternative current application. The $\mathrm{P} / \mathrm{M}$ FeSi is produced by pressing and sintering. The sintering temperature takes place at $1120{ }^{\circ} \mathrm{C}$ under endothermic protective atmosphere (Figure 8a) and under nitrogen - hydrogen (Figure 8b) and at 1290 ${ }^{\circ} \mathrm{C}$ under nitrogen - hydrogen (Figure 8c).

To illustrate the effect of the sintering conditions at various temperatures, a microstructural examination of the samples have been evaluated. The three microstructures of the Figure $8 \mathrm{a}$, Figure $8 \mathrm{~b}$ and Figure $8 \mathrm{c}$ illustrate clearly the effect of the sintering temperature and of the protective gas on the homogenization of the matrix [6-8]

The microstructure of the Figure $8 \mathrm{a}$ shows a mixture of ferrite and pearlite - a carburization takes place during the sintering process due to the endothermic protective atmosphere with the presence of a little quantity of a carbon gas. In contrary of this, in a proper protective atmosphere nitrogen - hydrogen the microstructure Figure $8 \mathrm{~b}$ consists of a pure ferrite. The sintering at $1120^{\circ} \mathrm{C}$ shows that the silicon - iron particles are not homogeneously distributed in the matrix (Figure 9). The intensity of the red coloration is an enrichment of Iron silicon power particles that are not dissolved in the matrix due to the low sintering temperature $1120^{\circ} \mathrm{C}$.

At a sintering temperature of $1290^{\circ} \mathrm{C}$ the pores are well rounded, smooth pores and no evidence of presence of silicon particles. (Figure 8c). The silicon enrichment are reduced and for this reason the silicon is homogeneous distributed in the matrix.

\section{Cooling}

The cooling rate in a sintering furnace is fat enough that a significant portion of the material matrix transforms to martensite $[9,10]$. That technique offers good manufacturing economy by providing a one step process together with good combination of strength, toughness and hardness. For the rapid cooling, the furnace atmosphere is sucked out of the muffle, cooled to temperatures below $100{ }^{\circ} \mathrm{C}$ and blown onto the parts. The ventilator's speed can be used to modified the cooling rates.

In order to get the microstructure hardened the sintered steels have to be alloyed with elements like $\mathrm{Mo}, \mathrm{Cr}$
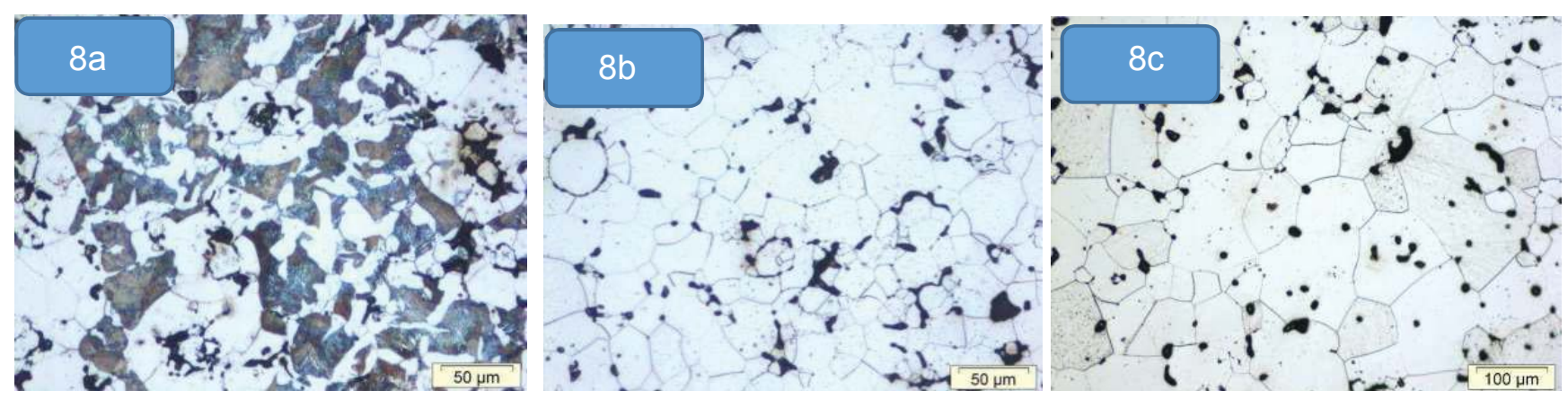

Figure 8: Influence of the sintering temperature and protective gas on the microstructure.
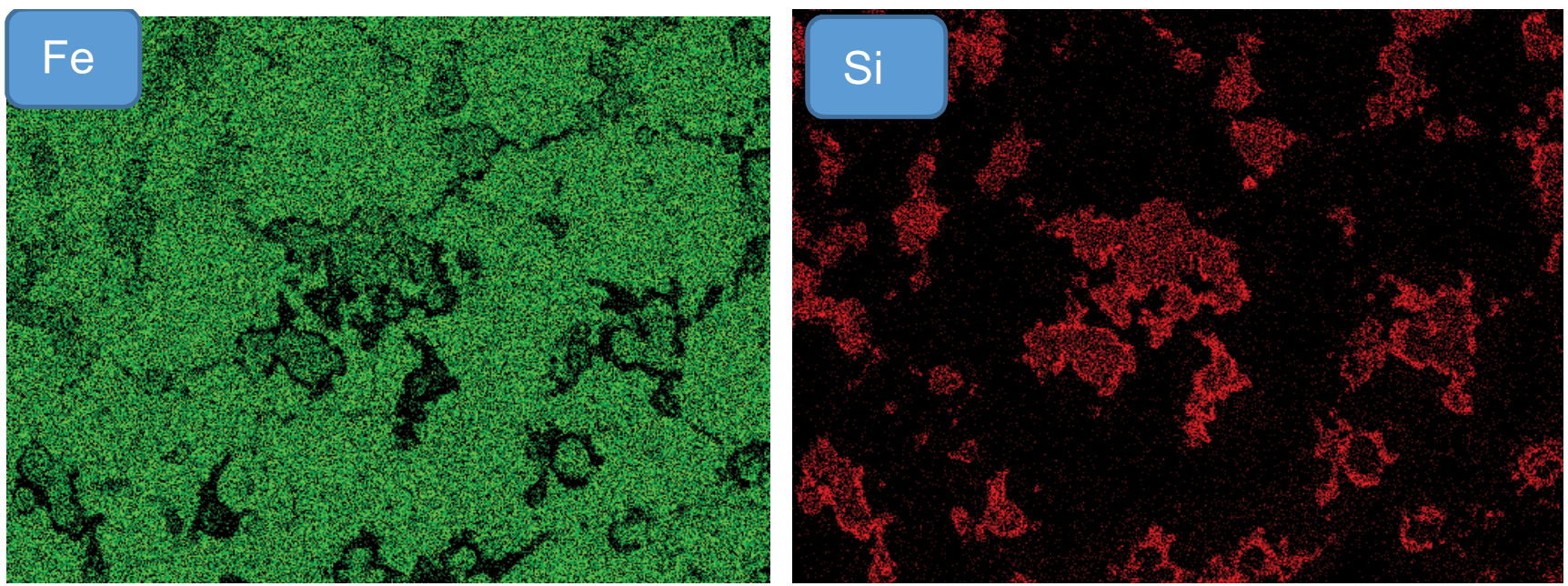

Figure 9: Mapping of the distribution of the elements Iron and Silicon (from Figure 8b). 
and $\mathrm{Cu}$ and they have to contain appropriate amounts of carbon. A decarburization during the sintering is not acceptable because this effect loads to a reduction of the carbon content and per consequent a diminution of the amount of martensite in the matrix.

\section{Conclusions} study.

The following conclusions have been drawn from this

- The dewaxing zone is the first step of the sintering manufacturing process and the choice of the parameter are important for the two next steps of the sintering.

- Temperature, time, protective atmosphere are the key for the success of the sintering.

- Understanding the role of the three steps of the sintering is critical to the production of quality sintered PM steels.

- A metallographic analysis is needed to achieve the understanding of the sintering process.

- The microstructure in unetched und etched state of the parts is used to explain and to interprete the metallurgical defects.

- The sintering process is the key to producing quality ferrous sintered material with high performance properties.

\section{References}

1. Lenel Fritz V (1980) Powder metallurgy: Principles and applications. Metal Powder Industries Federation, Princeton, New Jersey.
2. German RM (1984) Powder metallurgy science. Metal Powder Industries Federation, Princeton, New Jersey.

3. Durdaller C (1972) Furnace atmospheres. Technical Bulletin D174, Hoeganaes Corporation.

4. Jones WD (1960) Fundamental principles of powder metallurgy. London, 546.

5. Chan WH (1956) A dew point temperature diagramm for metal-metal oxide equilibria in hydrogen atmospheres. Welding Journal 35: 622-624.

6. Bocchini GF (2004) Influence of controlled atmosphere on the proper sintering of carbon steels. Powder Metallurgy Progress 4: 1-34.

7. Delarbre P, Schoppa A (2015) Einfluss der sinterbedingungen auf die mikrostruktur und die eigenschaften von sinterstählen. Pulvermetallurgie in Wissenschaft und Praxis, Fachverband Pulvermetallurgie, 31: 181-193.

8. Gonzalez F, Houbaert Y (2013) A review of ordering phenomena in iron-silicon alloys. Revista de Metallurgia 49: 178-199.

9. Jang G, Drozda M, Danninger $H$, Wibbeler $H$, Schatt $W$ (1984) Sintering behavior, mechanical and magnetic properties of sintered Fe-Si materials. The international Journal of Powder Metallurgy \& Powder Technology 20: 287-300.

10. James W Brian (1998) What is sinter-hardening? International Conference on Powder Metallurgy \& Particulate Materials, Las Vegas, USA.

11. Delarbre P, Sigl LS (2004) Sinterhärten von pm-stählen: grundlage und praktische anwendung. Pulvermetallurgie in Wissenschaft und Praxis, Fachverband Pulvermetallurgie, 31: 179-193. 